\title{
NEUTRALIDADE DA REDE DE INTERNET NO BRASIL: REGULAÇÃO, VIOLAÇÕES E A ATUAÇÃO DE ÓRGÃOS DE DEFESA DO CONSUMIDOR
}

\author{
ABEIN: Área 6 - Políticas Públicas e Regulação.
}

6.3 Políticas de regulação e Defesa do consumidor"

JEL: L5 - Regulation and Industrial policy

L50 - Geral

AUTORES:
\begin{tabular}{|l|l|}
\hline Walter Shima & $\begin{array}{l}\text { Doutor pelo IE/UFRJ e Professor do Programa de Pós-graduação em Políticas } \\
\text { Públicas (UFPR) }\end{array}$ \\
\hline $\begin{array}{l}\text { Lucas Henrique } \\
\text { Gonçalves }\end{array}$ & $\begin{array}{l}\text { Bibliotecário e Mestre em Políticas Públicas pelo Programa de Políticas } \\
\text { Públicas da UFPR }\end{array}$ \\
\hline $\begin{array}{l}\text { Almir Cléydison } \\
\text { Joaquim da Silva }\end{array}$ & $\begin{array}{l}\text { Graduado em Economia pela UFPB, mestre e doutorando pelo Programa de } \\
\text { Políticas Públicas da UFPR }\end{array}$ \\
\hline
\end{tabular}

RESUMO: Diversos países no mundo têm realizado discussões sobre o processo de formulação de políticas para regulação da Neutralidade da Rede (NR), ou seja, para regulamentação do tráfego de dados entre empresas detentoras de infraestrutura física para difusão do serviço de acesso à Internet (Internet Service Providers - ISP) e empresas produtoras ou distribuidoras de conteúdos, aplicativos e outros serviços acessados e utilizados por diversos usuários de Internet (Content Service Providers - CSP). Com a evolução das Tecnologias de Informação e Comunicação (TICs), tem-se observado uma sobreposição nas atividades das empresas ofertantes de serviços de conteúdo e de acesso à Internet, onde os ISPs estão entrando no mercado de produção e distribuição de serviços/produtos, antes de exclusividade dos CSPs, enquanto que estes últimos têm procurado desenvolver sua própria infraestrutura da rede para oferta de produtos. Isso possui implicações diretas tanto na concorrência dos ofertantes quanto na restrição de acesso a produtos e conteúdos da Internet, em desvantagem para os consumidores. A NR procura garantir a igualdade no tráfego de dados, independente do remetente, origem, destino, conteúdo, formato, tamanho e qualquer outra especificidade que venha a caracterizar um pacote de dados que trafega na rede. Nesse sentido, o trabalho objetiva apresentar uma discussão da atuação de entidades de defesa dos direitos dos consumidores na formulação de políticas para a regulação da NR no Brasil, assim como na identificação de violações à NR. Além de uma revisão de literatura sobre a NR e sua regulação, a abordagem metodológica parte da análise de casos de violações à NR no Brasil, especialmente a partir de dados do relatório desenvolvido por Intervozes e Derechos Digitales (2017). A análise destes casos dar-se-á juntamente com uma discussão do comportamento da regulação brasileira em favor (ou não) do consumidor. Por fim, verifica-se que as entidades de defesa dos direitos dos consumidores atuam de maneira ativa para manutenção da NR no Brasil, citando-se um dos principais casos de violação à NR do Brasil - o limite e o corte no tráfego de dados do serviço de acesso à Internet banda larga fixa.

Palavras-chave: Neutralidade da Rede; Políticas de Regulação; Defesa do Consumidor; Setor de Telecomunicações.

ABSTRACT: Divers countries around the world have held discussions on the process of formulating policies for the regulation of Network Neutrality (NR), that is, to regulate data traffic between companies that have physical infrastructure for the diffusion of the Internet access service (Internet Service Providers - ISP) and companies producing or distributing content, applications and other services accessed and used by various Internet users (Content Service Providers - CSP). With the evolution of Information and Communication Technologies (ICTs), there has been an overlap in the activities of companies offering content services and Internet access, where ISPs are entering the market of production and distribution of services / products, prior to CSPs' exclusivity, while CSPs have sought to develop their own network infrastructures for product offerings. This has direct implications both in the competition of the bidders and in the restriction of access to products and contents of the Internet, at a disadvantage for consumers. The NR seeks to ensure equality in data traffic, regardless of the sender, source, destination, content, format, size and any other specificity that will characterize a data packet that travels in the network. In this sense, the objective of this work is to present a discussion of the performance of consumer rights 
organizations in the formulation of policies for the regulation of NR in Brazil, as well as in the identification of NR violations. In addition to a literature review on NR and its regulation, the methodological approach starts from the analysis of cases of NR violations in Brazil, especially from data from the report developed by Intervozes and Derechos Digitales (2017). The analysis of these cases will be accompanied by a discussion of the behavior of Brazilian regulation in favor (or not) of the consumer. Finally, it is verified that the entities of defense of the rights of the consumers act in an active way to maintain the NR in Brazil, citing one of the main cases of violation to NR of Brazil - the limit and the cut in the data traffic of the fixed broadband Internet access service.

Key-words: Neutrality of the Network; Regulatory Policies; Consumer defense; Telecommunications industry.

\section{INTRODUÇÃO}

Com o desenvolvimento e introdução das Tecnologias de Informação e Comunicação (TICs) na vida cotidiana da sociedade moderna, o serviço de acesso à Internet tornou-se tão essencial quanto serviços de energia elétrica, telefonia, saúde, educação e outros serviços essenciais para o desenvolvimento socioeconômico de uma população. O serviço de acesso à Internet é gerenciado e ofertado por provedores de acesso à Internet (Internet Service Providers - ISP), os quais correspondem a empresas detentoras de infraestrutura física (cabos, antenas, fios, etc.) que possibilita a difusão deste serviço. Enquanto que os produtos (conteúdos, aplicativos e outros serviços) acessados e utilizados por diversos usuários de Internet são ofertados pelos provedores de serviços de conteúdo (Content Service Providers - CSP), que são empresas produtoras ou distribuidoras que utilizam a Internet como meio para ofertar seus serviços/produtos. Estes dois tipos de empresas são essenciais para o funcionamento da Internet, pois , por um lado, os ISPs possibilitam o tráfego de pacotes de dados pela infraestrutura da rede que é detentor e, por outro lado, os CSPs ofertam diversos serviços/produtos aos usuários de Internet. Ou seja, os serviços/produtos ofertados pelos CSPs trafegam como pacotes de dados pela infraestrutura da rede dos ISPs.

Com a evolução das TICs, dois cenários de sobreposição de atividades têm sido observados no âmbito das empresas ofertantes de serviços de conteúdo e de acesso à Internet, a saber: i) os ISPs estão adentrando o mercado de produção e distribuição de serviços/produtos, antes de exclusividade dos CSPs. Isto possibilita uma grande vantagem competitiva para os ISPs, pois estes já são detentores da infraestrutura física e tecnológica para a oferta destes serviços/produtos aos usuários de Internet; e ii) os CSPs, com grande poder financeiro, estão adentrando no mercado de infraestrutura da rede, visando desenvolver sua própria rede para oferta do serviço de acesso à Internet. Estes dois cenários são confirmados por Pita (2017) e Antonopoulos et al. (2017), que oferecem exemplos concretos de ISPs, como a AT\&T e a Verizon, que compraram CSPs, e exemplos de CSPs, como o Facebook e o Google, que iniciaram o desenvolvimento de infraestrutura de rede própria. Estas duas situações tendem a gerar novos modelos de negócios a serem ofertados aos usuários de Internet, como o zero-rating e a Content Delivery Network (CDN).

Neste contexto, a Neutralidade da Rede (NR) surge para garantir a igualdade no tráfego de dados, independente do remetente, origem, destino, conteúdo, formato, tamanho e qualquer outra especificidade que venha a caracterizar um pacote de dados que trafega na rede. Por conseguinte, a regulação sobre o serviço de acesso à Internet é fundamental, tendo em vista que a reorganização do mercado de Internet numa perspectiva tanto de diversificação de serviços/produtos ofertados quanto dos seus ofertantes -, necessita ser delineada para favorecer o bem estar da sociedade, e não apenas aos interesses das grandes corporações. Por este motivo, políticas públicas que visam à regulação do mercado de Internet, e atuações em prol da defesa do consumidor são fundamentais para a manutenção da qualidade do serviço ofertado e da garantia de respeito aos direitos dos consumidores, principalmente, em mercados em que o avanço tecnológico e comercial são céleres.

Feitas estas considerações, o presente trabalho objetiva apresentar uma discussão da atuação de entidades de defesa dos direitos dos consumidos na formulação de políticas para a regulação da NR no Brasil, assim como na identificação de violações à NR. Trata-se, portanto, de um tema atual e globalizado, onde diversos países estão em processo de discussão e formulação de estratégias para NR, via políticas de regulatórias. Além de uma revisão de literatura sobre a NR e sua regulação, a abordagem metodológica parte da análise de casos de violações à NR no Brasil, especialmente a partir de dados do relatório 
desenvolvido por Intervozes e Derechos Digitales (2017). A análise destes casos dar-se-á juntamente com uma discussão do comportamento da regulação brasileira em favor (ou não) do consumidor.

Por fim, este trabalho encontra-se estruturado em quatro seções, além da introdução e das considerações finais. A segunda seção apresenta uma discussão sobre a NR, acordos comerciais de ISPs e CSPs e a regulação da NR em âmbito mundial. A terceira seção trata da regulação enquanto aspecto direcionado a manutenção do bem estar social. Na quarta seção aborda a regulação da NR no Brasil e destaca alguns atentados à estrutura regulatória. Enquanto que na quinta seção discutem-se casos de violações à NR no Brasil.

\section{NEUTRALIDADE DA REDE: ACORDOS COMERCIAIS E REGULAÇÃO NO MUNDO}

Os estudos sobre NR começam a ganhar destaque na literatura a partir dos anos 2000, especialmente com as pesquisas de Tim $\mathrm{Wu}$, nos Estados Unidos. Ao considerar que alguns ISPs dos Estados Unidos estavam pleiteando a ideia de aumentar seu poder decisório sobre o tráfego dos pacotes de dados que transitam pela sua infraestrutura da rede, Wu (2006) expôs a principal questão acerca da NR: os ISPs querem ter poder de decisão sobre a aceleração e degradação da velocidade de serviços/produtos que trafegam sobre a infraestrutura da rede de que são detentores. Este aumento de poder decisório infringe a $\mathrm{NR}$, que prevê o livre trânsito a todos os pacotes de dados existentes na rede, sem interferência de qualquer agente, a não ser em caso de calamidade pública e/ou manutenção da garantia da qualidade dos serviços/produtos acessados pelo usuário. Com o avanço da discussão na literatura, questões sobre concorrência e competitividade passaram a fazer parte do debate da NR.

\subsection{ACORDOS COMERCIAIS DE ISPs E CSPs}

O intento de ganho de poder de monopólio dos ISPs e dos CSPs no mercado de Internet ampliaram as preocupações sobre o futuro da Internet. Estas preocupações permeiam os acordos comerciais feitos entre alguns ISPs e CSPs, estes últimos, na grande maioria das vezes, conglomerados empresariais com grande poder financeiro e penetração em diversos países, como o Facebook, o Google, o Whatsapp e a Netflix. Atualmente, dois tipos de acordos comerciais são preocupantes no no âmbito da NR: o zero-rating e a CDN. De modo geral, o zero-rating oferece ao usuário/cliente de um determinado ISP o acesso e uso a determinado serviço/produto sem que ocorra o desconto da franquia - ou cobrança - de dados da conexão de Internet contratada. Enquanto que a CDN é o uso de servidores para o armazenamento em cache de serviços/produtos de determinado CSP, para diminuir a distância entre os serviços/produtos deste CSP e o usuário/cliente de determinado ISP. Além destes, a tendência dos ISPs em adentrar o mercado de produção e distribuição de serviços/produtos, antes de exclusividade dos CSPs, também gera preocupação sobre as questões de concorrência e competitividade no mercado de Internet.

Para ilustrar casos concretos, apresenta-se abaixo um breve detalhamento de três experiências: a) iniciativa Internet.org; b) expansão da Akamai Technologies; e c) a entrada de ISPs no mercado de produção e distribuição de serviços/produtos, assim como da introdução de CSPs no mercado de infraestrutura da rede, buscando a criação da sua própria infraestrutura.

\section{a) Iniciativa Internet.org enquanto prática de zero-rating:}

A iniciativa Internet.org é uma proposta do Facebook e tem o objetivo de ofertar conexão à Internet gratuita para pessoas de países de baixa renda. Ao observar a finalidade geral desta iniciativa, verifica-se, em um primeiro momento, que o efeito da Internet.org é positivo, uma vez que procura incluir populações marginalizadas ao acesso à Internet, que de outro modo dificilmente ocorreria se fosse unicamente de responsabilidade dos governos de países menos desenvolvidos. Contudo, em uma análise mais aprofundada, percebe-se que esta iniciativa carrega uma problemática mais ampla. Ao tempo em que procura ofertar serviços de Internet gratuita para cidadãos de países menos desenvolvidos, esta iniciativa procura aumentar o poder de monopólio, assim como afetar as questão de concorrência e competividade 
que, por consequência, viola à NR. As pessoas que utilizam o Internet.org estão se conectando apenas a uma parcela da Internet e essa parte é determinada pelo operador comercial do projeto (OECD, 2016). A iniciativa Internet.org é caracterizada como uma prática de zero-rating, pois o projeto oferece o acesso a serviços/produtos parceiros do Facebook e não da Internet como um todo, e ainda, não possui protocolos de segurança que garantam a proteção sobre as informações dos cidadãos que utilizarem a Internet.org (18MILLIONRISING.ORG et al., 2015).

Mourão e Barbosa $(2015$, p. 1) sintetizam a problemática e a relação conflituosa existente na Internet.org ao indicarem que "a propaganda da maior corporação do mundo digital atual diz que esta é uma forma de conectar aqueles sem qualquer acesso à Internet. Do outro lado, estão organizações de defesa dos direitos dos usuários que lutam por um acesso integral da rede para todos" (MOURÃO; BARBOSA, 2015). A Internet.org se caracteriza como uma prática para aumentar os usuários e mercados de atuação do Facebook (KNIBBS, 2015). O que seria legítimo se não violasse a NR e não ferisse a concorrência e competividade entre os CSPs, pois impede o acesso e uso de serviços/produtos que não são parceiros da rede social. De acordo com um grupo de organizações defensoras da NR, a Internet.org afetará a liberdade de expressão, igualdade de oportunidades, segurança, privacidade e inovações regionais, assim como poderá facilitar a vigilância do tráfego de dados de usuários por governos autoritários e antidemocráticos. Isso ocorre a partir do momento que a Internet.org se torna o único ponto de controle centralizado para o livre fluxo de informações (18MILLIONRISING.ORG et al., 2015).

\section{b) Akamai Technologies e o serviço de CDN:}

A Akamai Technologies é uma empresa de tecnologia que atua no serviço de CDN no mercado de Internet global. De modo geral, uma CDN é uma rede de diversos servidores interligados à Internet e instalados em diversos locais físicos pelo mundo afora, a fim de diminuir a distância entre a captura e a entrega dos pacotes de dados de determinado serviço/produto acessado pelo usuário/cliente de um ISP (AKAMAI, 2018). Este serviço possibilita que CSPs com poder financeiro elevado adquiram CDN para viabilizar que seus serviços/produtos, solicitados pelos usuários, possam ser acessados de maneira mais rápida, devido à diminuição no trafego dos pacotes de dados pela infraestrutura da rede. Bem como, permite aos ISPs agilizar o tráfego de determinados serviços/produtos, tendo em vista o grande acesso dos seus usuários/clientes a estes serviços/produtos.

De acordo com Ciriaco (2014), as CDNs são serviços muito utilizados de maneira global, pois além de agilizarem a transferência dos pacotes de dados entre os CSPs e o usuário, também são mais baratas do que a ampliação da infraestrutura da rede. Neste contexto, a CND é solução para a parcela de CSPs que pode pagar pelo serviço e para a parcela de usuários que contrata a conexão de Internet do ISP, parceiro destes CSPs. Por conseguinte, a depender do uso da CDN, pode-se observar a existência de violação à NR. Isso ocorre pelo fato da CDN afetar a concorrência e a competitividade entre os CSPs e os ISPs, pois os pacotes de dados destes serviços/produtos terão seu tráfego mais ágil em comparação com outros serviços/produtos de mesma característica.

Com relação à violação à NR, a discussão sobre a CDN é controverso, pois diferentemente do zerorating, o acesso a outros serviços/produtos disponíveis na rede se mantém e, também, não ocorre degradação de serviços/produtos dos CSPs não parceiros dos ISPs, e nem priorização ou cobrança pelos serviços/produtos dos CSPs parceiros dos ISPs. Por outro lado, os ISPs podem utilizar-se da CDN para armazenarem os serviços/produtos desenvolvidos por ele mesmo, e se negar a utilizar CDN de CSPs que ofertem serviços/produtos concorrentes ao seu, o que poderia caracterizar a CND como uma prática que beneficia determinados serviços/produtos disponível na Internet.

\section{c) A nova tendência no mercado de Internet:}

A nova tendência existente no mercado de Internet é a seguinte: i) CSPs que ofertam serviços/produtos por meio da infraestrutura da rede de ISPs, estão desenvolvendo sua própria infraestrutura da rede; e ii) ISPs, detentores da infraestrutura da rede, visualizaram no mercado de produção e distribuição de serviços/produtos um eixo para ampliarem seus negócios e suas receitas. De acordo com Pita (2017), a 
AT\&T, um ISP norte-americano anunciou a compra da Time Warner, um CSP; a Verizon, outro ISP norteamericano, anunciou a compra da Yahoo, um CSP; a Vivendi, CSP francês, lançou uma plataforma de vídeo em parceria com o ISP Vivo; o ISP Telefônica Brasil anunciou a compra de ações do CSP Terra Networks Brasil. De acordo com Antonopoulos et. al. (2017), o Facebook e o Google já iniciaram esforços para instalarem cabos de fibra óptica por todo o Oceano Pacífico, enquanto a Akamai Technologies, vem implantando milhares de servidores ao redor do mundo.

Esta movimentação empresarial no mercado de Internet amplia o uso das práticas zero-rating e CDN. Ao considerar que CSPs e ISPs estarão atuando em áreas comuns do mercado de Internet, ambos poderão fazer uso das práticas de zero-rating e CDN para intensificar o uso dos serviços/produtos desenvolvidos por eles ou dos seus parceiros. O caso é mais alarmante para os CSPs, pois a criação e manutenção de uma infraestrutura da rede é muito mais onerosa do que a produção e/ou distribuição de serviços/produtos. Assim sendo, esta nova tendência pode vir a prejudicar ainda mais a concorrência e competividade entre os ISPs e CSPs, gerando possíveis monopólios no mercado Internet, uma vez que os ISPs e CSPs que adentrarem nesta nova visão empresarial terão o controle de toda a cadeia de acesso e uso de serviços/produtos da Internet.

A possibilidade de que uma mesma empresa possua o controle sobre todo o processo de acesso e uso da Internet propaga o poder de monopólio sobre o mercado de Internet, pois empresas novas estarão em um ambiente de competição desigual. A esse respeito, serviços/produtos disponíveis na Internet que já estejam consolidados possuem maiores e melhores chances de evoluir e aumentar sua lucratividade, enquanto outras empresas podem nem vir a ter a chance de surgir ou se estabelecer devido ao cenário de acordos comerciais que priorizem ou condicionem os usuários ao acesso e ao uso de determinados serviços/produtos. Neste cenário, a regulação da NR é a prática que poderá impedir esta distorção no mercado de Internet, pois determinará que a escolha do usuário de acesso e uso aos serviços/produtos disponíveis na rede seja de acordo com a sua necessidade e não pela política de gerenciamento da rede efetuada pelo ISP contratado (WU, 2002).

\subsection{A REGULAÇÃO DA NEUTRALIDADE DA REDE NO MUNDO}

A regulação da NR pelo mundo é diversificada. Existem países que já definiram suas regulações, enquantooutros que apenas propuseram diretrizes para o bom funcionamento da rede, assim como existe parcela significativa de países queainda estão em processo de discussão do tema.

Foram elencados alguns países para apresentar este panorama global da regulação da NR. O quadro 1 apresenta um compilado das regulações dos seguintes países e órgãos de regulação: Brasil, Agência Nacional de Telecomunicações (ANATEL); Estados Unidos, Federal Communications Commission (FCC); África do Sul, Independent Communications Authority of South Africa (ICASA); Japão, Ministry of Internal Affairs and Communications (MIC); Coréia do Sul, Korea Communications Commission (KCC); Austrália, Australian Communications and Media Authority (ACMA); e países membros da União Europeia, Body of European Regulators for Electronic Communications (BEREC).

Quadro 1 - Panorama Global da Regulação da NR em países selecionados

\begin{tabular}{|c|c|c|}
\hline País & Órgão regulador & Principais aspectos da regulação da NR $^{1}$ \\
\hline Brasil & $\begin{array}{l}\text { Agência Nacional de } \\
\text { Telecomunicações } \\
\text { (ANATEL) }\end{array}$ & $\begin{array}{l}\text { O Brasil possui uma regulação denominada Marco Civil da Internet (Lei }{ }^{\circ} \\
12.965 \text {, de } 23 \text { de abril de } 2014 \text { ), que proíbe os ISPs }{ }^{2} \text { de cobrarem taxas extras } \\
\text { dos usuários, de discriminarem o tráfego dos dados na rede e obriga as } \\
\text { empresas a tratarem os dados de forma igual, independentemente do } \\
\text { conteúdo, origem ou uso do serviço/produto. Tal lei é regulamentada pelo } \\
\text { Decreto } n^{\circ} 8.771 \text {, de } 11 \text { de maio de } 2016 \text {. }\end{array}$ \\
\hline $\begin{array}{c}\text { Estados } \\
\text { Unidos }\end{array}$ & $\begin{array}{c}\text { Federal } \\
\text { Communications } \\
\text { Commission (FCC) }\end{array}$ & $\begin{array}{l}\text { Até dezembro de } 2017 \text {, os Estados Unidos possuía o documento FCC 15-24: } \\
\text { Report and Order on Remand, Declaratory Ruling, and Order, de } 26 \text { de } \\
\text { fevereiro de 2015, que garantia a manutenção da Internet livre no país, } \\
\text { quando a FCC (com base na Lei de Comunicação de } 1934 \text { e da Lei de } \\
\text { Telecomunicações de 1996) reclassificou o serviço de acesso à Internet como } \\
\text { um serviço de telecomunicações. As regras visavam proteger a liberdade de }\end{array}$ \\
\hline
\end{tabular}




\begin{tabular}{|c|c|c|}
\hline & & $\begin{array}{l}\text { expressão dos usuários, incentivando a inovação e a promoção de } \\
\text { investimentos na infraestrutura fixa e móvel da rede dos Estados Unidos, e } \\
\text { ainda, proibia o bloqueio e a aceleração das conexões, a priorização por meio } \\
\text { de taxas extras cobradas dos usuários, a discriminação de conteúdos para } \\
\text { usuários específicos e a discriminação ou vantagem de serviços/produtos. No } \\
\text { dia } 14 \text { de dezembro de } 2017 \text {, a FCC decidiu (por } 3 \text { votos a } 2 \text { ) que o serviço } \\
\text { de Internet voltará a ser classificado como serviços de informação nos } \\
\text { Estados Unidos e aumentará a exigência de transparência por parte dos ISPs } \\
\text { com relação aos seus acordos comerciais e planos de Internet ofertados aos } \\
\text { cidadãos americanos (GOMES, 2017). }\end{array}$ \\
\hline $\begin{array}{l}\text { África do } \\
\text { Sul }\end{array}$ & $\begin{array}{c}\text { Independent } \\
\text { Communications } \\
\text { Authority of South } \\
\text { Africa (ICASA) }\end{array}$ & $\begin{array}{l}\text { Embora o governo da África do Sul não possua uma regulação que instaure } \\
\text { o princípio da NR no país, o ICASA está discutindo uma nova legislação das } \\
\text { TICs }{ }^{3} \text { do país e já se pronunciou publicamente a favor de uma política que } \\
\text { favoreça a NR, com vistas a cumprir a constituição do país e acabar com o } \\
\text { gargalo de acesso digital. }\end{array}$ \\
\hline Japão & $\begin{array}{c}\text { Ministry of Internal } \\
\text { Affairs and } \\
\text { Communications } \\
\text { (MIC) }\end{array}$ & $\begin{array}{l}\text { O Japão possui recomendações enunciadas em } 2006 \text { e reforçadas em } 2007 \text {, } \\
\text { pelo MIC, a saber: i) acesso a todos os conteúdos e serviços; ii) conexão com } \\
\text { qualquer terminal que atenda aos padrões técnicos; e iii) uso de redes a um } \\
\text { preço razoável sem discriminação. E ainda, o MIC desenvolveu pesquisas de } \\
\text { competitividade utilizando as diretrizes da NR que resultaram em novas } \\
\text { recomendações, apresentadas em } 2008 \text {, como a equidade dos custos e do uso } \\
\text { da rede, a compreensão mais detalhada sobre o tráfego da rede, a revisão da } \\
\text { regulação dominante e a promoção da diversificação das formas de acesso à } \\
\text { rede. }\end{array}$ \\
\hline $\begin{array}{l}\text { Coréia do } \\
\text { Sul }\end{array}$ & $\begin{array}{c}\text { Korea } \\
\text { Communications } \\
\text { Commission (KCC) }\end{array}$ & $\begin{array}{l}\text { As diretrizes para o gerenciamento do tráfego da rede na Coréia do Sul são } \\
\text { apresentadas no relatório da KCC, Annual Report 2011: Broadcasting and } \\
\text { Telecommunications Policy Accomplishments in Graphs, publicado em } \\
\text { 2012. O relatório destaca os seguintes tópicos: i) direitos do usuário; ii) } \\
\text { transparência no tráfego da rede; iii) proibição de bloqueio iv) proibição de } \\
\text { discriminação não razoável; e v) gestão razoável do tráfego da rede. Em } 2013 \\
\text { e } 2014 \text { foram publicadas diretrizes mais específicas sobre a transparência do } \\
\text { gerenciamento do tráfego da rede, assim como a exigência da permissão de } \\
\text { uso de VoIP4 móvel a todos os cidadãos, porém, o governo ainda possibilita } \\
\text { que os ISPs diferenciem os preços e a quantidade de dados de conexão } \\
\text { utilizados pelos serviços de VoIP móvel. }\end{array}$ \\
\hline Austrália & $\begin{array}{c}\text { Australian } \\
\text { Communications and } \\
\text { Media Authority } \\
\text { (ACMA) }\end{array}$ & $\begin{array}{l}\text { A Austrália não possui regulação sobre o tema NR. O debate público sobre a } \\
\text { NR começou em } 2015 \text { no país e perdura até os dias atuais sem que tenha } \\
\text { havido a instauração de alguma regulação que proíba a discriminação não } \\
\text { razoável do tráfego dos dados na rede e/ou os acordos comerciais que podem } \\
\text { prejudicar a NR. }\end{array}$ \\
\hline $\begin{array}{l}\text { Países } \\
\text { membros } \\
\text { da União } \\
\text { Europeia }\end{array}$ & $\begin{array}{l}\text { Body of European } \\
\text { Regulators for } \\
\quad \text { Electronic } \\
\text { Communications } \\
\quad \text { (BEREC) }\end{array}$ & $\begin{array}{l}\text { Em 2016, foram publicadas, pelo BEREC, as diretrizes da NR para os países } \\
\text { membros da União Europeia, o BEREC Guidelines on the Implementation } \\
\text { by National Regulators of European Net Neutrality Rules. As diretrizes são } \\
\text { direcionadas aos órgãos reguladores dos países membros, e apresentam } \\
\text { clareza quanto à implantação de serviços especializados e solidificam } \\
\text { medidas neutras para o gerenciamento do tráfego da rede, conforme segue: i) } \\
\text { deve-se salvaguardar o tratamento igual entre os serviços/produtos } \\
\text { disponíveis na Internet; ii) deve-se avaliar se durante o tráfego dos pacotes } \\
\text { de dados o tratamento dado aos dados trafegados são iguais e se há a real } \\
\text { necessidade de efetuar tratamento diferenciado para as situações } \\
\text { emergenciais; e iii) deve-se assegurar que os ISPs divulguem as informações, } \\
\text { de fácil acesso e compreensão, quanto ao gerenciamento do tráfego dos } \\
\text { dados. }\end{array}$ \\
\hline
\end{tabular}

Fonte: elaboração própria, com base em Global Net Neutrality Coalition (2017); Setenareski (2017)

Nota: ${ }^{1} \mathrm{NR}=$ neutralidade da rede $;{ }^{2} \mathrm{ISPs}=$ Internet Service Providers $;{ }^{3} \mathrm{TICs}=$ Tecnologia de Informação e Comunicação $;{ }^{4}$ VoIP $=$ Voz sobre Internet Protocol. 
Pela análise do quadro 1, verifica-se a diversidade entre as regulações da NR pelo mundo, e também sua fragilidade. O caso dos Estados Unidos, que havia concretizado a questão da NR no governo Barack Obama, retomou a discussão do tema no governo Donald Trump, e a alterou. O quadro também mostra que a regulamentação da NR ainda não é vista como uma regulação necessária para guiar a evolução da Internet em todos os países. E, ainda, mesmo após a definição e implantação de um regime de NR, este pode ser modificado a partir do entendimento dos governantes. Por este motivo, a atuação de entidades que objetivam a defesa do consumir torna-se necessária tanto para acompanhar possíveis desregulamentações da NR em desfavor do consumidor quanto para atuar e colaborar na formulação destas regulações.

\section{AS REGULAÇÕES E A ATUAÇÃO DOS ORGÃOS DE DEFESA DO CONSUMIDOR}

As intervenções estatais, por meio da regulação, procuram agir para correção ou contraposição das falhas de mercado, assim como para garantia de ganhos de bem-estar social. Ao apresentar uma discussão sobre o processo de regulação econômica, Viscusi, Vernon e Harrington (1992) destacam o papel e influência que as decisões do governo exercem sobre o bem-estar dos agentes e na forma como se comportam. Neste contexto, ao assumir o papel de regulador, o governo pode restringir as escolhas dos agentes econômicos por meio do seu poder de coagir. Em sentido convergente, Pinheiro e Saddi (1992, p. 254) consideram a regulação como um "conjunto de regras que limitam a liberdade de ação ou de escolha das empresas, dos profissionais liberais e/ou dos consumidores, e cuja aplicação é sustentada pelo poder de coerção que a sociedade concede ao Estado". Cabe destacar a distinção que os autores fazem entre regulação e regulamentação, a primeira sendo realizada pela intervenção estatal em um plano mais elevado e geral, enquanto que a segunda compreende o detalhamento normativo da intervenção.

Em geral, a regulação econômica está vinculada as restrições impostas sobre decisões de preço, quantidade, e entrada e saída de empresas em determinados setores. Enquanto que as variáveis que, via de regra, escapam ao controle da regulação referem-se a qualidade de produtos e ao nível de investimento, que podem se configurar como importantes estratégias de competição entre indústrias. Cabe ressaltar que na medida em que um setor é regulado, a eficiência alocativa e produtiva do desempenho da indústria é codeterminado por forças do mercado e por processos administrativos (VISCUSI; VERNON; HARRINGTON, 1992).

Para compreender os efeitos da regulação, três teorias podem ser destacadas, a saber: 1) teoria positivista (ou teoria do interesse público), que considera a regulação atuando em indústrias por falhas de mercado e na tentativa de corrigir práticas desiguais; 2) teoria da captura, considera que os reguladores são "capturados" pelas indústrias, ou seja, suas estratégias são pró-industrias; e 3) teoria econômica da regulação, considerando que o bem-estar de diferentes grupos de interesses são melhoradas pela regulamentação (VISCUSI; VERNON; HARRINGTON, 1992).

Por outro lado, Faraco (2012) apresenta uma discussão sobre direito concorrencial e regulação, onde destaca o caráter complementar e conflitante que ambas as modalidades de atuação estatal podem assumir sobre a economia. Apesar das diferenças, tanto o direito concorrencial quanto a regulação tratam dos mesmos tipos de relações econômicas. Um elemento comum reside no alcance de correção das falhas de mercado, ou seja, quando a ação privada dos agentes se distancia dos objetivos coletivos. E no que concerne às distinções, o autor destaca que o direito concorrencial é abordado enquanto perspectiva disciplinadora da ação de agentes econômicos, podendo controlar o exercício do poder econômico e deter a posição de monopólio. Enquanto que a regulamentação visa a criação de um ambiente econômico mais concorrencial, por meio da restrição da liberdade do agente econômico (FARACO, 2012).

$\mathrm{Na}$ tentativa de estabelecer critérios de aplicação do direito concorrencial em setores regulados, Faraco (2012) aponta algumas situações, como por exemplo que: a caracterização de um setor tido como "regulado" não elimina a incidência do direito concorrencial, pois alguns aspectos das relações econômicas dos mesmos podem não ser tratados pela regulação; a regulação pode não ser efetivamente aplicada, sendo insuficiente para conter determinado poder econômico; e a regulação pode ser muito abrangente, onde não haveria espaço para a aplicação do direito concorrencial (situação de monopólio natural). Nestas situações 
haveria um elemento de complementaridade entre o direito concorrencial e a regulação na disciplina do poder econômico. (FARACO, 2012).

No que concerne ao modelo regulatório brasileiro, Salgado (2003) chama a atenção para o novo aparato institucional que surge na década de 1990, especialmente a partir da reorientação do papel do Estado na economia. Baseado em princípios de livre-iniciativa, livre-concorrência e de defesa dos consumidores, diversos órgãos de defesa da concorrência, dos consumidores e agências reguladoras são criadas - em um contexto de recém-privatização de alguns serviços públicos, como as telecomunicações, geração e distribuição de energia elétrica, saneamento básico e dentre outros. No caso do setor de telecomunicações, a criação da Agência Nacional de Telecomunicações (Anatel), enquanto órgão regulador e com autonomia administrativa e financeira, tem papel significativo no estabelecimento de garantias regulatórias em prol do bem estar social (SALGADO, 2003; CUZA, 2008). Ainda de acordo com Salgado (2003, p. 21), "as agências reguladoras cumprem o duplo papel de estruturar mercados onde antes só havia a atuação estatal, e de garantir que esses mercados se pautem por regras predefinidas. A concorrência é sempre o parâmetro que guia a atuação legal das agências em ambas as funções”.

\section{NEUTRALIDADE DA REDE NO BRASIL: REGULAÇÃO E ATENTADOS}

Em 2009 o Comitê Gestor da Internet no Brasil (CGI.br) publicou a primeira iniciativa para o funcionamento da Internet no Brasil - a Resolução CGI.br/RES/2009/003/P de 2009. Este documento contém 10 princípios essenciais para a manutenção adequada da Internet. $\mathrm{O}$ sexto princípio trata sobre a NR, o qual é apresentado da seguinte maneira: " 6 . Neutralidade da rede - Filtragem ou privilégios de tráfego devem respeitar apenas critérios técnicos e éticos, não sendo admissíveis motivos políticos, comerciais, religiosos, culturais, ou qualquer outra forma de discriminação ou favorecimento" (CGI.br, 2009). Com o avanço das discussões sobre o funcionamento da Internet no Brasil, a Secretaria de Assuntos Legislativos do Ministério da Justiça e a Escola de Direito do Rio de Janeiro lançaram um projeto para a construção colaborativa de um Projeto de Lei (PL) que objetivasse o funcionamento da Internet no Brasil (SETENARESKI, 2017).

Estas duas iniciativa, do CGI.br e do projeto colaborativo, contribuíram para a formulação do PL 2.126/11, que estabelecia os princípios, as garantias, os direitos e os deveres para o uso da Internet no Brasil. Juntamente com a tramitação deste PL nos órgão governamentais competentes, o PL 84/99, e posteriormente o PL 2.793/11 procurava estabelecer uma Lei de Crimes Cibernéticos no país. O PL 84/99 ficou conhecido como AI-5 Digital, em referência a Ditadura Militar no Brasil, pois em seu processo de formulação buscava-se estabelecer a identificação dos usuários que viessem a utilizar a Internet - essa ação ficou conhecida como "mordaça digital" (INTERVOZES; DERECHOS DIGITALES, 2017). De modo geral o PL no 84/99 destacava aspectos penais e tipificava os crimes na esfera digital (BRASIL, 2012).

Durante todo o processo de discussão do PL ${ }^{\circ}$ 84/99, setores de áreas da cultura, dos direitos humanos e de tecnologia mobilizaram-se contrários ao PL e requeriam uma regulação de ordem civil e não penal (INTERVOZES; DERECHOS DIGITALES, 2017). Mesmo com o avanço das discussões sobre as questões civis e de funcionamento da Internet no Brasil, a Lei de Crimes Cibernéticos foi promulgada dois anos antes do Marco Civil da Internet (Lei no 12.965, de 23 de abril de 2014). O Marco Civil da Internet além de assegurar o regime de NR no Brasil, por meio do seu art. $9^{\circ}$ da seção I, o "responsável pela transmissão, comutação ou roteamento tem o dever de tratar de forma isonômica quaisquer pacotes de dados, sem distinção por conteúdo, origem e destino, serviço, terminal ou aplicação" (BRASIL, 2014), prevê, também, questões como liberdade de expressão, transparência, ampla defesa e proteção ao consumidor, acessibilidade tecnológica, proteção dos dados, segurança, e liberdade nos negócios comerciais.

De acordo com Setenareski (2017), entre os anos de 2014 e 2015 foram abertas consultas públicas visando à criação de regulamentação da NR no Brasil. Nestas consultas, diversas instituições participaram, entre elas ANATEL, Ministério da Justiça (MJ) e o CGI.br. Em 2016, o Decreto 8.771/16 foi criado e promulgado. Este decreto estrutura o sistema de proteção à NR no Brasil e estabelece as obrigações de cada agente institucional, visando garantir a eficiência do regime de NR no país. Neste cenário, o CGI.br é a 
entidade com função de estabelecer as diretrizes para o funcionamento da Internet e manutenção da NR no Brasil. A ANATEL é tida como o órgão fiscalizador da infraestrutura da rede e de questões técnicas que possam surgir. O Conselho Administrativo de Defesa Econômica (CADE) e a Secretaria de Acompanhamento Econômico do Ministério da Fazenda (SAE) são os órgãos responsáveis por apurar as denúncias e infrações à NR.

Além de apresentar as funções dos órgãos, este decreto também apresenta determinações sobre o tratamento isonômico que os ISPs devem dar ao tráfego dos dados na rede, a transparência na divulgação das práticas a serem adotadas pelos ISPs para manter a qualidade da rede, a liberdade para quebra da NR em casos de serviços de emergência, a proibição para os acordos comerciais que violem à NR, e a manutenção da segurança da rede e do sigilo dos dados informacionais que nesta trafegam. De modo geral, por meio do Marco Civil da Internet e do Decreto 8.771/16 está em vigência no Brasil um regime que aplica à NR no funcionamento da rede de Internet. Entretanto, como dito anteriormente, o regime de NR é frágil e pode sofrer diversos atentados por parte da iniciativa privada, que é responsável pela oferta do serviço de acesso à Internet aos cidadãos brasileiros, ou por parte dos parlamentares brasileiros, quando são contrários aos princípios da NR. Alguns casos são apresentados a seguir:

\section{a) O limite e o corte no tráfego de dados do serviço de Internet banda larga fixa:}

A contratação de dados de Internet para o uso em dispositivos móveis é prática tradicional no Brasil, e a contratação de plano de Internet fixa também. A primeira é passível de acabar dependendo da quantidade de uso dos dados pelo usuário, que neste caso ou é ofertada uma nova contratação de pacote de dados adicional ou é feita a redução da velocidade da conexão utilizada. Enquanto que no caso do plano fixo, a conexão da Internet não é interrompida, independente da quantidade de uso desta conexão. No ano de 2016, alguns ISPs brasileiros atentaram contra essa liberdade ininterrupta de oferta da Internet fixa no Brasil. As três maiores empresas responsáveis pelo serviço de oferta à Internet fixa se posicionaram da seguinte forma a UOL (2016, p. 1): i) a Oi informou que o "contrato de prestação de serviço aponta o acesso ilimitado à rede como uma medida promocional, renovada automática e mensalmente, mas que pode ser suspensa mediante comunicação prévia da operadora"; ii) a Vivo/GVT confirmou "que vai adotar a franquia de consumo de dados de Internet fixa, mas só para "novos clientes"'; e iii) a Claro/NET informou que "indica uma franquia de dados a ser utilizada dependendo do plano e, estabelece a redução da velocidade para os clientes que atingirem o limite contratado".

A situação proposta pelos ISPs brasileiros mostra uma clara intenção em maximizar seus lucros em detrimento da qualidade da conexão de Internet fixa ofertada aos usuários de Internet. Ferrari (2016) afirma que o usuário que utilizar toda a sua franquia de dados de Internet contratada pela via fixa, só terá a mesma reestabelecida após o pagamento de nova taxa ou após o fim do mês, ou seja, a oferta da Internet fixa seria semelhante à oferta da Internet móvel. Diversas manifestações surgiram após a exposição da intensão das empresas brasileiras. Destacamos os posicionamentos da ANATEL, do CGI.br e da PROTESTE organização sem fins lucrativos e sem vinculação com empresa ou partido política, que objetiva o fortalecimento dos direitos dos consumidores brasileiros.

Inicialmente a ANATEL não interveio sobre a polêmica do limite de Internet via fixa. Pelo contrário, Carlos Baigorri, superintendente de Competição da ANATEL considerou que a limitação é benéfica aos usuários soft, ou seja, aqueles que utilizam pouco a Internet, pois estes pagam o mesmo valor que os usuários que possuem alto consumo de dados de Internet (GROSSMANN, 2016). O superintendente indica também que "o estabelecimento de pacotes de preço pelo uso efetivo do consumo, acaba com a falsa noção do 'ilimitado' e permite que o consumidor pague exatamente pelo que ele gasta" (AQUINO, 2016). Diante deste cenário, o CGI.br aprovou e divulgou a Resolução CGI.br/RES/2016/015, que apresenta a recomendação de que "qualquer decisão a respeito do atual debate sobre franquia de dados na banda larga fixa no Brasil deve ser embasada por estudos técnicos, jurídicos e econômicos com validade legal, teórica e empírica, observando-se também a experiência internacional a respeito" (CGI.br, 2016).

Além disso, o CGI.br reafirma que soluções colaborativas são essenciais para manter o desenvolvimento da Internet no Brasil, e deve-se levar em conta o uso de consulta pública e práticas que atendam de maneira equilibrada os diversos eixos afetados pela proposta de limite e corte no tráfego dos 
dados da Internet ofertada por via fixa. Em sentido convergente, a PROTESTE encampou a campanha "Diga não ao bloqueio de sua Internet fixa". A petição online obteve mais de 170 mil adesões (PROTESTE, 2017), e a organização efetuou um pedido de liminar contra os ISPs que ofertam Internet por via fixa para que estes não possam “[...] comercializar novos planos com previsão de bloqueio à conexão após fim da franquia do $3 \mathrm{G}$ e da internet fixa. E que sejam obrigadas a adequar suas práticas na contratação do serviço de conexão à internet aos termos do Marco Civil" (PROTESTE, 2016, p. 1). Atualmente o processo $\mathrm{n}^{\circ}$ 1045633-86.2015.8.26.0100 ainda está em tramitação no Tribunal de Justiça de São Paulo.

Após diversos protestos, entre eles do CGI.br e da PROTESTE, a ANATEL, divulgou um despacho em que determina que os ISPs não pratiquem a redução e nem a suspensão da velocidade contratada, ou que efetuem cobranças de taxas extras aos usuários (BRASIL, 2016), até que a questão fosse debatida pelos órgãos e instâncias competentes no país. Diante das manifestações contrárias à possibilidade de limitar a Internet banda larga no Brasil, alguns parlamentares, como Eunício Oliveira (PMDB-CE), Humberto Costa (PT-PE) e Ricardo Ferraço (PSDB-CE) se manifestaram sobre o tema, resultando na aprovação do PL ${ }^{\circ}$ 174/2016 no Senado Federal, e remetido à Câmara dos Deputados como PL no 7.182/2017. Este PL propunha a inclusão do "inciso XIV no art. $7^{\circ}$ da Lei 12.965 de 23 de abril de 2014, para vedar a implementação de franquia limitada de consumo nos planos de Internet banda larga fixa" (BRASIL, 2017a, p. 1). Após um ano de audiências públicas para aprofundar a discussão sobre o tema, o PL ainda continua em tramitação nas Comissões de Defesa do Consumidor; Ciência e Tecnologia, Comunicação e Informática, e Constituição e Justiça e de Cidadania da Câmara dos Deputados (BRASIL, 2017b).

\section{b) A alteração da regulação dos Estados Unidos:}

No fim de 2017, os Estados Unidos alterou sua regulação da NR. Isto afetou a discussão em grande parte do mundo e reviveu a discussão sobre as regulações já instauradas em diversos países. De acordo com Wiziack (2017), as operadoras brasileiras pretendem solicitar ao governo brasileiro a revisão do Marco Civil da Internet, visando à liberdade nos negócios de oferta de Internet no Brasil. Os ISPs brasileiros afirmam que a atual tecnologia dos equipamentos que estruturam a Internet consegue efetuar práticas de gerenciamento de tráfego da rede que priorizem pacotes de dados específicos e sem que haja a interferência na velocidade contratada pelo usuário, o que não afetaria o princípio da NR (WIZIACK, 2017). Neste cenário, os ISPs almejam maior flexibilidade nas regras do Marco Civil da Internet para que possam efetuar acordos comerciais da maneira que desejarem.

O Sindicato Nacional das Empresas de Telefonia e de Serviços Móvel Celular e Pessoal (SINDITELEBRASIL) lançou nota após a alteração da regulação nos Estados Unidos, em que defendem a flexibilização nas regras que regulam a NR no Brasil e, ainda, afirmam que a regulação brasileira deve permitir que o gerenciamento do tráfego de dados seja feito da maneira que os detentores da rede, os ISPs, desejem e que o governo brasileiro deve ampliar e tornar mais efetiva a fiscalização sobre o mercado de Internet no Brasil (BRASIL, 2017a).

\section{c) Os PLs que tramitam na Câmara dos Deputados:}

Levantamento realizado pelas Organizações não governamentais (ONGs) Intervozes e Derechos Digitales (2017) indicam que até maio de 2017 estavam em tramitação na Câmara dos Deputados 44 projetos de leis (PLs) que tinham, em alguma medida, a intenção de alterar o Marco Civil da Internet. Os PLs que afetam diretamente a NR são os que possuem os temas de ampliação da possibilidade de bloqueio de aplicações e, também, de permissão ou regulação da franquia de dados contratada pelo usuário. Onde 4 PLs interferem diretamente a NR, na medida em que "propõem a ampliação das possibilidades de bloqueio de aplicações, principalmente para fins de investigação criminal, o que tornaria as exceções, previstas atualmente na lei, uma prática não mais excepcional e, sim, recorrente" (INTERVOZES; DERECHOS DIGITALES, 2017, p. 153).

A existência de PLs que afetam a NR demonstra que uma parcela dos parlamentares brasileiros estão dispostos a alterar a regulação existente no Brasil em favor das empresas, pois não concordam com as regras imposta por esta regulação. Neste cenário, o Ministério da Ciência, Tecnologia, Inovações e Comunicações 
(MCTI) afirmou que o governo brasileiro não pretende efetuar nenhuma alterações na regulação atual da NR no país, e ainda Flávia Lefèvre, conselheira do CGI.br, e Rafael Zanatta, membro do Instituto Brasileiro de Defesa do Consumidor (IDEC) avaliam que alterar leis no Brasil não é tão simples quanto nos Estados Unidos, considerando as estruturas políticas e burocráticas do país (BRASIL, 2017a).

\section{CASOS DE VIOLAÇÕES À NEUTRALIDADE DA REDE NO BRASIL}

Na literatura brasileira e mundial é difícil encontrar casos que demonstrem violações à NR. Muitas vezes pelo fato da complexidade que envolve a identificação das possíveis violações cometidas. Diversas variáveis interferem diretamente na detecção das violações à NR, entre elas a diversidade das regulações que pode existir nos países por onde o pacote de dados trafega. Outra variável determinante para identificar a violação à NR é a denúncia por parte do usuário/cliente que foi lesado. E ainda, é necessária de alguma forma a contratação de plano de dados dos ISPs durante um determinado período para verificar a violação à NR. Entretanto, as ONGs Intervozes e Derechos Digitales (2017) analisaram alguns planos de dados ofertados pelas empresas brasileiras, e citam uma série de violações à NR no Brasil que ocorrem na oferta do serviço de acesso à Internet.

Na grande maioria estas violações são configuradas como acordos comerciais firmados, ou não, entre ISPs e CSPs e, também, atuação de ordem judicial no âmbito do Brasil, conforme argumentado pelas ONGs, onde

Ações comerciais, principalmente no âmbito das operadoras de telefonia móvel, e até judiciais podem ser compreendidas como violação do princípio da Neutralidade de Rede, uma vez que, para se efetivarem, precisam tecnicamente discriminar datagramas, não se configurando como os casos de exceção previstos em lei (INTERVOZES; DERECHOS DIGITALES, 2017, p. 149).

As ONGs Intervozes e Derechos Digitales (2017) elencaram alguns casos que comprovam violação à regulação brasileira, conforme sistematizados no quadro 2 .

Quadro 2 - Violações à NR no Brasil - casos identificados por empresas de ISPs

\begin{tabular}{|c|l|}
\hline Empresas ISPs & \multicolumn{1}{|c|}{ Casos de violação à regulação da NR brasileira } \\
\hline \multirow{5}{*}{ Vivo/GVT } & $\begin{array}{l}\text { Efetuação de bloqueio da conexão de Internet após o término da franquia de dados de Internet } \\
\text { móvel }\end{array}$ \\
\cline { 2 - 3 } & Prática de zero-rating, a partir da oferta gratuita do Facebook e do Twitter ao usuário/cliente \\
\cline { 2 - 3 } & $\begin{array}{l}\text { Prática de zero-rating, ao não descontar da franquia de dados dos seus usuários/clientes o } \\
\text { acesso e uso do aplicativo iFood; o bloqueio, por meio judicial, dos pacotes de dados que } \\
\text { trafegavam pelo aplicativo WhatsApp }\end{array}$ \\
\hline \multirow{5}{*}{ Oi } & $\begin{array}{l}\text { Prática de zero-rating, com a oferta gratuita (sem desconto da franquia de dados) do seu } \\
\text { aplicativo de música }\end{array}$ \\
\cline { 2 - 3 } TIM & $\begin{array}{l}\text { Prática de zero-rating, ao não descontar da franquia de dados dos seus usuários/clientes o } \\
\text { acesso e uso do aplicativo iFood; o bloqueio, por meio judicial, dos pacotes de dados que } \\
\text { trafegavam pelo aplicativo WhatsApp }\end{array}$ \\
\hline \multirow{5}{*}{ Claro/NET } & $\begin{array}{l}\text { Prática de zero-rating, ao oferecer de maneira gratuita todos os seus aplicativos próprios ao } \\
\text { usuário/cliente e parcialmente o aplicativo WhatsApp, além de oferecer um plano especifico } \\
\text { denominado Turbo WhatsApp }\end{array}$ \\
\cline { 2 - 3 } & $\begin{array}{l}\text { Prática de zero-rating, ao não descontar da franquia de dados dos seus usuários/clientes o } \\
\text { acesso e uso do aplicativo iFood; o bloqueio, por meio judicial, dos pacotes de dados que } \\
\text { trafegavam pelo aplicativo WhatsApp }\end{array}$ \\
\hline & $\begin{array}{l}\text { Prática de zero-rating, com oferta de Facebook, WhatsApp e Twitter gratuitos até o fim do } \\
\text { plano contratado pelo usuário/cliente }\end{array}$ \\
\hline $\begin{array}{l}\text { Prática de zero-rating, ao não descontar da franquia de dados dos seus usuários/clientes o } \\
\text { acesso e uso do aplicativo iFood; o bloqueio, por meio judicial, dos pacotes de dados que } \\
\text { trafegavam pelo aplicativo WhatsApp }\end{array}$ \\
\hline
\end{tabular}


Fonte: elaboração dos autores, a partir de Intervozes e Derechos Digitales (2017).

Outra questão que atinge a NR é a iniciativa Internet.org, apresentada anteriormente. O Ministério Público Federal (MPF) considerou que a implantação desta iniciativa no Brasil viola à NR, pois limita o acesso a serviços/produtos específicos e, ainda, pode excluir serviços/produtos que sejam contrários aos ideais do Facebook, empresa responsável pela iniciativa (MOURÃO; BARBOSA, 2015). Por outro lado, o Conselho Administrativo de Defesa Econômica (CADE) afirmou que ofertar serviços/produtos sem que haja o desconto da franquia de dados contratada pelo usuário não infringe à NR (HIGA, 2017). O MCTI considera que a prática de zero-rating pode ser prejudicial à sociedade, mas informou que a fiscalização das violações à NR é de competência da ANATEL, e esta avaliou que a prática de zero-rating efetuada pelos ISPs brasileiros não dão indícios de infrações à legislação (INTERVOZES; DERECHOS DIGITALES, 2017).

Essa diferença de entendimento entre os órgãos brasileiros mostra a complexidade sobre o tema da NR. A Associação Brasileira de Internet (ABRANET) e a PROTESTE, consideram que a prática de zerorating é prejudicial à NR. Ao ser solicitado para maiores explicações, o CADE ponderou que a prática de zero-rating não degrada ou prioriza a velocidade dos pacotes de dados dos aplicativos, mas que a oferta ocorre de maneira diferenciada aos usuários/clientes, assim como considera que o governo brasileiro não deve desestimular as inovações nos modelos de negócios das empresas (INTERVOZES; DERECHOS DIGITALES, 2017; HIGA, 2017).

\section{CONSIDERAÇÕES FINAIS}

Este artigo introduziu o tema NR e apresentou dois tipos de acordos comerciais (zero-rating e CDN) que tendem a violar à NR. Neste cenário, os órgãos de defesa do consumidor se fazem necessários para manter o bem estar à sociedade, considerando que ainda não há consenso sobre a regulação da NR, especialmente quando se trata de acordos comerciais.

O zero-rating é visto como prejudicial ao mercado de Internet, quando favorece determinados tipos de serviços/produtos. Entretanto, quando o favorecimento se dá uma categoria de serviços/produtos (aplicativos de mensagens, redes sociais, jogos online, páginas de notícias, músicas, e-mail, streaming de vídeos) a prática de zero-rating pode ser vista como permissível, pois estaria dando a mesma oportunidade aos CSPs que são concorrentes entre si. A CND pode ser vista como uma prática que não viola à NR, considerando que os pacotes de dados de determinado serviço/produto não são priorizados, mas estão mais próximos geograficamente do usuário/cliente, o que automaticamente possibilita o tráfego dos dados mais rápido.

Entretanto, a priorização de serviços/produtos afeta a entrada de novas empresas no mercado de Internet, pois ajuda os ISPs dominantes a manterem seu status de dominância. Por este motivo, se faz necessária a atuação de fiscalização dos órgãos de defesa do consumidor. E a fiscalização sobre as violações à NR só é possível quando a regulação de um país apresenta tais violações. Porém, a regulação existente deve ser direta e abrangente, para que possa englobar as maiores possibilidades de violação à NR e, ainda, deve apresentar um texto que não gere dupla interpretação.

A regulação existente no Brasil apresenta proibições de acordos comerciais e gerenciamento de tráfego dos dados que violem à NR. Entretanto, isto não foi suficiente para que entidades governamentais tivessem o mesmo entendimento sobre uma mesma situação que afeta o mercado de Internet. Neste caso, a atuação de ONGs que objetivam preservar os direitos dos consumidores é essencial para mostrar ao governo a atuação contraditória sobre a legislação e, principalmente, o que isto afeta a sociedade. Além disso, as ONGs são, em muitas vezes, as instituições que fiscalizam as atuações dos ISPs no mercado de Internet, como pode ser visto na atuação das ONGs Intervozes e Derechos Digitales. É certo afirmar que a fiscalização sobre as violações à NR são mais efetivas quando possuem a participação dos usuários/clientes lesados, para tanto o arcabouço regulatório deve ser bem definido. Setenareski et al. (2017) desenvolveu o Observatório da Neutralidade da Rede (ONR), https://observatorio.c3sl.ufpr.br/neutralidadedarede, que 
objetiva a publicização de documentos sobre à NR e, também, possibilita a denúncia de práticas que violem à NR no Brasil.

Os casos expostos por Intervozes e Derechos Digitales (2017) deixam clara a violação à NR no Brasil. E os atentados à NR (especialmente os PLs que tramitam na Câmara dos Deputados e a solicitação de limite/corte à Internet ofertada por via fixa no Brasil, bem como a atual regulação da NR nos Estados Unidos) mostram a fragilidade do tema. Soma-se a isto o posicionamento do CADE sobre a autorização da prática de zero-rating, que em alguma medida afetam à NR. Neste cenário, as organizações que atuam em alguma medida na defesa do consumidor (PROTESTE, Intervozes, Derechos Digitales e CGI.br) foram atuantes, pois questionaram as entidades e se posicionaram contrárias a qualquer alteração na atual legislação brasileira. Em suma, os atentados à NR no Brasil e a ineficiência de fiscalização e penalização sobre as violações à NR mostram que as entidades governamentais brasileiras tentem a favorecer as empresas que ofertam o serviço de acesso à Internet, e por isso a atuação das ONGs no Brasil são essenciais para o bom funcionamento do mercado de Internet brasileiro.

\section{REFERÊNCIAS}

18MILLIONRISING.ORG et al. Open Letter to Mark Zuckerberg Regarding Internet.org, Net Neutrality, Privacy, and Security.[s.1.], 2015. Disponível em:

<https://www.facebook.com/notes/accessnoworg/open-letter-to-mark-zuckerberg-regarding-Internetorgnet-neutrality-privacy-and-/935857379791271> Acesso em: 30 out 2017

AQUINO, Miriam. Limite de dados em franquia é bom para usuário, defende técnico da ANATEL. [s.1], 2016. Disponível em: <http://www.telesintese.com.br/limite-de-dados-apos-franquia-e-bom-parausuario-defende-tecnico-da-ANATEL> Acesso em: 19 fev 2017

AKAMAI. What is a CDN server?. [s.1], 2014. Disponível em:

<https://www.akamai.com/uk/en/cdn/what-is-a-cdn.jsp> Acesso em: 07 abr 2018

ANTONOPOULOS, Angelos et. al. Shedding Light on the Internet: stakeholders and network neutrality. IEEE Communications Magazine, 2017. Disponível em: <https://www.researchgate.net/publication/313847624> Acesso em: 31 jul 2017

BRASIL. Lei n. 12.965, de 23 de abril de 2014. Estabelece princípios, garantias, direitos e deveres para o uso da Internet no Brasil. Brasília, 2014. Disponível em:

<http://www.planalto.gov.br/ccivil_03/_ato2011-2014/2014/lei/112965.htm> Acesso em: 16 dez 2017

BRASIL. AGÊNCIA BRASIL. Fim da neutralidade de rede nos EUA pode ter impactos na Internet no Brasil. [s.1], 2017a. Disponível em: <https://istoe.com.br/fim-da-neutralidade-de-rede-nos-eua-podeter-impactos-na-Internet-no-brasil/> Acesso em: $16 \mathrm{dez} 2017$

BRASIL. AGÊNCIA NACIONAL DE TELECOMUNICAÇÕES. ANATEL suspende mudanças na banda larga fixa e exige mais transparência para acompanhamento da franquia. [s.1], 2016. Disponível em: <http://www.ANATEL.gov.br/institucional/ultimas-noticiass/1093-decisao-cautelarsuspende-reducao-da-velocidade-da-banda-larga-fixa-apos-termino-da-franquia-2> Acesso em: 19 fev 2017

BRASIL. CÂMARA DOS DEPUTADOS. Projeto de Lei n. 84 de 1999. Dispõe sobre os crimes cometidos na área de informática, suas penalidades e dá outras providências. Brasília, 2012b. Disponível em: <http://www.camara.gov.br/proposicoesWeb/fichadetramitacao?idProposicao=15028> Acesso em: $19 \operatorname{dez} 2017$ 
BRASIL. CÂMARA DOS DEPUTADOS. Projeto de Lei n. 7.182 de 2017. Acrescenta inciso XIV ao art. $7^{\circ}$ da Lei $n^{\circ} 12.965$, de 23 de abril de 2014, para vedar a implementação de franquia limitada de consumo nos planos de Internet banda larga fixa. Brasília, 2017b. Disponível em:

<http://www.camara.gov.br/proposicoesWeb/fichadetramitacao?idProposicao=2126316> Acesso em 16 $\operatorname{dez} 2017$

CGI.br - COMITÊ GESTOR DA INTERNET NO BRASIL. Resolução CGI.br/RES/2009/003/P. São Paulo, 2009. Disponível em: <https://www.

CGI.br/resolucoes/documento/2009/CGI.br_Resolucao_2009_003.pdf> Acesso em: 20 jun 2017

CGI.br - COMITÊ GESTOR DA INTERNET NO BRASIL. Resolução CGI.br/RES/2016/015. [s.1], 2016. Disponível em: <http://cgi.br/resolucoes/documento/2016/015> Acesso em: 19 fev 2017

CIRIACO, Douglas. O que é uma CDN e como ela controla a internet que você usa?. [s.1], 2014. Disponível em: <https://www.tecmundo.com.br/internet/54073-o-que-e-uma-cdn-e-como-ela-controla-ainternet-que-voce-usa-.htm> Acesso em: 07 abr 2018

CUZA, Luiz. O regulador: elemento essencial para garantir conquistas. In: SALGADO, Lucia Helena; MOTTA, Ronaldo Seroa da. Regulação e Concorrência no Brasil Governança Incentivos e Eficiência. IPEA, 2008, p.291-300.

FARACO, Alexandre Ditzel. Aplicação das normas gerais de concorrência em setores regulados. In: MARTINEZ, Ana Paula (Org.). Temas atuais de direito da concorrência. Editora Singular, 2012, p. 359391.

FERRARI, Bruno. Operadoras de banda larga desafiam o bom senso do consumidor. [s.1], 2016. Disponível em: <http://epoca.globo.com/vida/experiencias-digitais/noticia/2016/04/operadoras-de-bandalarga-desafiam-o-bom-senso-do-consumidor.html> Acesso em: 19 fev 2017

GLOBAL NET NEUTRALITY COALITION. Net Neutrality. [s. 1], 2017. Disponível em: <https://www. thisisnetneutrality. org> Acesso em: 20 jun 2017

GOMES, Helton Simões. EUA decretam 'fim' da neutralidade de rede e decidem que provedor pode controlar acesso à Internet. [s.1], 2017. Disponível em:

$<$ https://g1.globo.com/economia/tecnologia/noticia/eua-decretam-fim-da-neutralidade-de-rede-edecidem-que-provedor-pode-controlar-acesso-a-Internet.ghtml> Acesso em: $16 \mathrm{dez} 2017$

GROSSMANN, Luís Osvaldo. Para ANATEL, franquia de dados na Internet fixa favorece quem consome pouco. [s.1], 2016. Disponível em:

$<$ http://convergenciadigital.uol.com.br/cgi/cgilua.exe/sys/start.htm?UserActiveTemplate=site\&infoid=41 676\&sid=4> Acesso em: 19 fev 2017

HIGA, Paulo. Cade diz que WhatsApp sem descontar da franquia não viola neutralidade de rede. [s.1.], 2017. Disponível em: <https://tecnoblog.net/222653/zero-rating-whatsapp-gratis-neutralidade-redecade> Acesso em: 30 out 2017

INTERVOZES; DERECHOS DIGITALES. Neutralidade de rede na América Latina: regulamentação, aplicação da lei e perspectivas - os casos do Chile, Colômbia, Brasil e México. São Paulo: Intervozes; Santiago: Derechos Digitales, 2017. 177p. Disponível em:

$<$ http://intervozes.org.br/publicacoes/neutralidade-de-rede-na-america-latina-regulamentacao-aplicacaoda-lei-e-perspectivas-os-casos-do-chile-colombia-brasil-e-mexic/> Acesso em 16 dez 2017 
KNIBBS, Kate. As razões pelas quais o projeto Internet.org do Facebook está sendo criticado. [s.1.], 2015. Disponível em: <http://gizmodo.uol.com.br/Internet-org-facebook-criticas> Acesso em: 30 out 2017

MOURÃO, Mônica; BARBOSA, Bia. Ministério Público considera projeto Internet.org, do Facebook, ilegal. [s.1.], 2015. Disponível em:

<https://www.cartacapital.com.br/blogs/intervozes/ministerio-publico-considera-projeto-Internet-org-dofacebook-ilegal-3972.html> Acesso em: 30 out 2017

OECD - ORGANIZATION FOR ECONOMIC CO-OPERATION AND DEVELOPMENT. Economic and Social Benefits of Internet Openness.[s. 1]: OECD, 2016. Disponível em: <http://www. oecd. org/officialdocuments/publicdisplaydocumentpdf/?cote=DSTI/ICCP(2015)17/FINAL\&docLanguage=En > Acesso em: 20 jun 2017

PINHEIRO, Armando Castelar; SADDI, Jairo. Regulação dos serviços públicos. In: PINHEIRO, Armando Castelar; SADDI, Jairo. Direito, economia e mercados. Rio de Janeiro: Elsevier, 2006, p. 253-291.

PITA, Marina. Teles avançam na verticalização e ameaçam CSPs. [s.1.], 2017. Disponível em: <https://www.cartacapital.com.br/blogs/intervozes/teles-avancam-na-verticalizacao-e-ameacamprovedores-de-conteudo-online> Acesso em: 31 jun 2017

PROTESTE. Diga não ao bloqueio de sua Internet fixa. [s.1], 2017. Disponível em: <http://www.proteste.org.br/nossas-lutas/diga-nao-ao-bloqueio-da-sua-Internet-fixa> Acesso em: $16 \mathrm{dez}$ 2017

PROTESTE. Para PROTESTE, limite à internet fixa é ilegal. [s.1], 2016. Disponível em: $<$ https://www.proteste.org.br/institucional/imprensa/press-release/2016/para-proteste-limite-a-internetfixa-e-ilegal> Acesso em: 19 fev 2017

SALGADO, Lucia Helena. Agências regulatórias na Experiência Brasileira: um panorama do atual desenho institucional. Brasília: IPEA, 2003.

SETENARESKI, Ligia Eliana. Criação de um observatório como forma de monitorar a Neutralidade da Rede no Brasil. 2017. 175 f. Tese (Doutorado em Ciência da Computação) - Programa de PósGraduação em Informática, Universidade Federal do Paraná, Curitiba. 2017. No prelo

SETENARESKI, Ligia; GARRETT, Thiago; PERES, Letíci; BONA, Luis; DUARTE JR.; Elias. Fiscalização da Neutralidade da Rede: Conceitos e Técnicas. In: SIMPOSIO BRASILEIRO DE REDES DE COMPUTADOS E SISTEMAS DISTRIBUÍDOS, 35., Belém. Anais... Porto Alegre: Sociedade Brasileira de Computação, 2017. p. 153-202. Disponível em: <https://sbrc2017.ufpa.br/wpcontent/uploads/2017/05/proceedingsMinicurso2017.pdf> Acesso em 05 mar 2018

UOL. Sua operadora vai adotar o limite da Internet fixa? [s.1], 2016. Disponível em: $<$ https://tecnologia.uol.com.br/noticias/redacao/2016/04/14/veja-quais-os-planos-de-sua-operadora-parao-limite-da-Internet-fixa.htm> Acesso em: 19 fev 2017

VISCUSI, W. Kip; VERNON, John M.; HARRINGTON, Joseph E. Introduction to economic regulation. In: VISCUSI, W.; VERNON, J.; HARRINGTON, J. Economics of regulation and antitrust. Cambridge, Mass.: Heath and Company, 2a ed., 1992, p. 307-350. 
WIZIACK, Julio. No Brasil, teles também vão pedir mudança de neutralidade de rede. [s.1], 2017. Disponível em: <http://www1.folha.uol.com.br/mercado/2017/12/1943511-no-brasil-teles-tambem-vaopedir-mudanca-de-neutralidade-de-rede.shtml> Acesso em: 16 dez 2017

WU, Tim. A Proposal for network neutrality.Charlottesville, 2002. Disponível em: <http://www. timwu. org/OriginalNNProposal. pdf> Acesso em: 19 jun 2017

WU, Tim. Network neutrality: competition, innovation, and nondiscriminatory access. Social Science ElectronicPublishing, 2006. Disponível em: <http://dx. doi. org/10. 2139/ssrn. 903118> Acesso em: 17 abr 2017 